\title{
Pozzolanic Reaction in Clayey Soils for Stabilization Purposes: A Classical Overview of Sustainable Transport Geotechnics
}

\author{
Kennedy C. Onyelowe $\mathbb{D}^{1,2}$ Michael E. Onyia $\mathbb{D D}^{3}{ }^{3}$ Duc Bui Van $\mathbb{D}^{4},{ }^{4}$ Haci Baykara $\mathbb{D}^{5},{ }^{5}$ \\ and Hyginus U. Ugwu ${ }^{6}$ \\ ${ }^{1}$ Department of Mechanical and Civil Engineering, Faculty of Engineering, Kampala International University Western Campus, \\ Ishaka, Uganda \\ ${ }^{2}$ Research Group of Geotechnical Engineering, Construction Materials and Sustainability, \\ Hanoi University of Mining and Geology, Hanoi, Vietnam \\ ${ }^{3}$ Department of Civil Engineering, Faculty of Engineering, University of Nigeria, Nsukka, Nigeria \\ ${ }^{4}$ Research Group of Geotechnical Engineering, Construction Materials and Sustainability, \\ Hanoi University of Mining and Geology, Hanoi, Vietnam \\ ${ }^{5}$ National Laboratory of Thermal Testing of Building Materials, Escuela Superior Politecnica Del Litoral (ESPOL), \\ Guayaquil, Ecuador \\ ${ }^{6}$ Department of Mechanical Engineering, Michael Okpara University of Agriculture, Umudike P. M. B. 7267, Umuahia 440109, \\ Abia State, Nigeria
}

Correspondence should be addressed to Duc Bui Van; buivand738@gmail.com

Received 16 December 2020; Revised 4 March 2021; Accepted 5 March 2021; Published 26 March 2021

Academic Editor: Robert Černý

Copyright ( 2021 Kennedy C. Onyelowe et al. This is an open access article distributed under the Creative Commons Attribution License, which permits unrestricted use, distribution, and reproduction in any medium, provided the original work is properly cited.

\begin{abstract}
Problematic soil stabilization processes involve the application of binders to improve the engineering properties of the soil. This is done to change the undesirable properties of these soils to meet basic design standards. However, very little attention has been given to the reactive phase of soil stabilization. This phase is the most important in every stabilization protocol because it embodies the reactions that lead to the bonding of the dispersed particles of clayey soil. Hence, this reactive phase is reviewed. When clayey soils which make up the greatest fraction of expansive soil come in contact with moisture, they experience volume changes due to adsorbed moisture that forms films of double diffused layer on the particles. When this happens, the clayey particles disperse and float, increasing the pore spaces or voids that exist in the soil mass. Stabilizations of these soils are conducted to close the gaps between the dispersed clayey soil particles. This is achieved by mixing additives that will release calcium, aluminum, silicon, etc., in the presence of adsorbed moisture, and a hydration reaction occurs. This is followed by the displacement reaction based on the metallic order in the electrochemical series. This causes a calcination reaction, a process whereby calcium displaces the hydrogen ions of the dipole adsorbed moisture and displaces the sodium ion responsible for the swelling potential of clayey soils. These whole processes lead to a pozzolanic reaction, which finally forms calcium alumina-silica hydrate. This formation is responsible for soil stabilization.
\end{abstract}

\section{Introduction}

The concept of pozzolanization in the fields of geoenvironmental engineering, geotechnical, and earth work as a whole is little talked about and little understood by experts and researchers. However, this concept is at the center of soil stabilization for clayey expansive soils and for the whole family of lateritic soils $[1,2]$. The pozzolanic reaction has been expressed and defined in different ways according to different experts. First, pozzolanas are construction materials possessing binding characteristics, which are applied in holding together the particles of a mass being worked on $[3,4]$. In this context, pozzolanization is the process of binding particles together to form a workable mass of a 
construction material [3]. According to the British Standard International [5] and American Standard for Testing and Materials [6], pozzolanas are materials possessing alumina $\left(\mathrm{Al}_{2} \mathrm{O}_{3}\right)$, silica $\left(\mathrm{SiO}_{2}\right)$, and ferrite $\left(\mathrm{Fe}_{2} \mathrm{O}_{3}\right)$, with the sum total of their composition by weight equal to or greater than $70 \%$. Cement, fly ash, ground granulated blast furnace slag, bitumen, quicklime, hydrated lime, calcite, etc., have been in use as conventional binders having fulfilled the above minimum standard requirements, in various civil engineering and earth works $[5,6]$. This is because they possess cementitious properties. Another group of materials which possesses similar properties is ash. Ash has been derived from the direct combustion of biomass or solid waste materials. These materials have been applied to improve the properties of soil in the earth and improve the properties of concrete, asphalt, etc., in other civil engineering areas of responsibility [7-9]. In geoenvironmental earth works, clayey soils have been at the center of all construction activities in the formation of foundations for road pavement, airfield pavement, landfill, backfills, embarkments, slope stability problems, etc. [8]. It is of serious concern to understand the behavior of clayey soils as they form the major element of various structures. Worthy of consideration in this work is the behavior of clayey soils when exposed to moisture effects. This is important because clayey soils as they are utilized as construction materials cannot be handled without molding moisture, which triggers the reactions in the clay leading to stabilization [7, 9]. Thus also, it is, after construction, due to the rise and fall of the water table, and foundations made of clayey soil are constantly exposed to moisture, either by runoff, migration through cracks, or capillary action [10]. The most important aspect of this investigation is the role moisture plays in the pozzolanic reaction that occurs in the faces, edges, and planes of clayey soils during soil stabilization procedures $[8,10]$. Clayey soils have the capacity to swelling immediately as they come in contact with moisture. During this state of moisture percolation, the clay minerals become charged with the negative ion on the surface and positive ions on the edge $[3,8]$. The adsorbed moisture also dissociates to its dipole forming hydrogen $\left(\mathrm{H}^{+}\right)$and hydroxyl $\left(\mathrm{OH}^{-}\right)$ions presented in Figure 1. This process is called hydration of the clayey soil where the soil is impregnated with moisture to its optimum content [3]. Due to the problematic properties of the clayey soil as a result of its erratic behavior, it is technically important that such problematic soils are treated with modifiers or binders that trigger processes that will lead to agglomeration of the particles that must have dispersed when moisture was introduced. Conventionally, cement, which contains primarily calcium oxide $(\mathrm{CaO})$, is used during this stabilization process. In addition, in recent years, due to the carbon footprint of cement, the utilization of environmentally friendly materials like ash has been on the rise. According to previous research results, ash is an amorphous material known for its high composition of aluminosilicates (Al-Si-Fe), which satisfies the design standard conditions $[5,6,11]$. For this reason, they release ionized metals such as $\mathrm{Al}^{3+}, \mathrm{S}^{2+}$, and $\mathrm{Fe}^{3+}$, and research has shown that these metallic compounds trigger pozzolanic reactions [3, 12-14]. When clayey soil particles disperse due to moisture impregnation, the particles form double diffused layers, which keeps them separated to overcome van der Waals intergranular particles. And during organic or inorganic additive stabilization, hydration reaction, calcination, and carbonation reactions occur. A replacement reaction between these processes occurs between hydrogen ions and calcium, aluminum, and silicon ions. Because these other metallic ions are higher in the electrochemical series $\left(\mathrm{Li}^{+}<\mathrm{Na}^{+}<\mathrm{H}^{+}<\mathrm{K}^{+}<\mathrm{NH}_{4}^{+}<\mathrm{Mg}^{2+}<\mathrm{Ca}^{2+}<\mathrm{Al}^{3+}<\mathrm{Fe}^{2+}\right)$ than hydrogen, they tend to displace it within the adsorbed moisture to form flocs. Furthermore, the sodium ion attached to octahedral and tetrahedral structures of the clay is replaced under the same principle and this removes its swelling components from the clayey soil [3, 8, 14-16]. This whole process is called the pozzolanic reaction. The primary objective of this work is to review the pozzolanic reaction as it affects the stabilization of clayey soils. The emphases or focus are on the utilization of organic- and inorganic-based additives.

\section{Review of Literature}

2.1. Electrochemical Series and Pozzolanic Reaction in Treated Clayey Soils. The reactive activities in a soil stabilization process and precisely at the phase of pozzolanic reaction where displacement reactions happen depend fundamentally on the arrangement of the metallic oxides in the electrochemical series $[3,17-20]$. This is an arrangement of the metal in the order of their oxidation $[3,8,17]$. Table 1 presents this order whereby the displacement of one metal by another is determined by the respective positions in the series. Once the elements released during a soil stabilization procedure are identified, it will be possible to identify the outcome of an additive soil stabilization process [15-18]. As can be seen from the table, the hydrogen ion from the dipolar water molecule of the adsorbed moisture that triggers the hydration reaction is lowest in the series compared to all other metallic elements released during additive soil stabilization. Hence, the replacement of hydrogen ions is very possible within the adsorbed complex or double diffused layer of clay particles.

2.2. Clayey Soils. Clayey soils are characterized by certain dominant minerals in their lattice structure $[4,7,8]$. During a soil stabilization procedure, it is a prerequisite to identify the dominant mineral present in any clayey soil being studied for improvement by applying the X-ray fluorescence method (XRF) [4-7]. Table 2 presents the possible minerals that can be found in any clayey soil. These minerals determine the basic characteristics of the clayey soil. This is due to their tetrahedral or octahedral arrangement [4]. These minerals also determine the interaction between clayey soil and moisture [3]. For instance, the three major minerals of kaolinite, illite, and montmorillonite determine the activity, plasticity, and expansive nature of clayey soil $[4,7,8]$. As soon as these minerals are identified, working of clayey soils to improve their problematic properties would not be any 

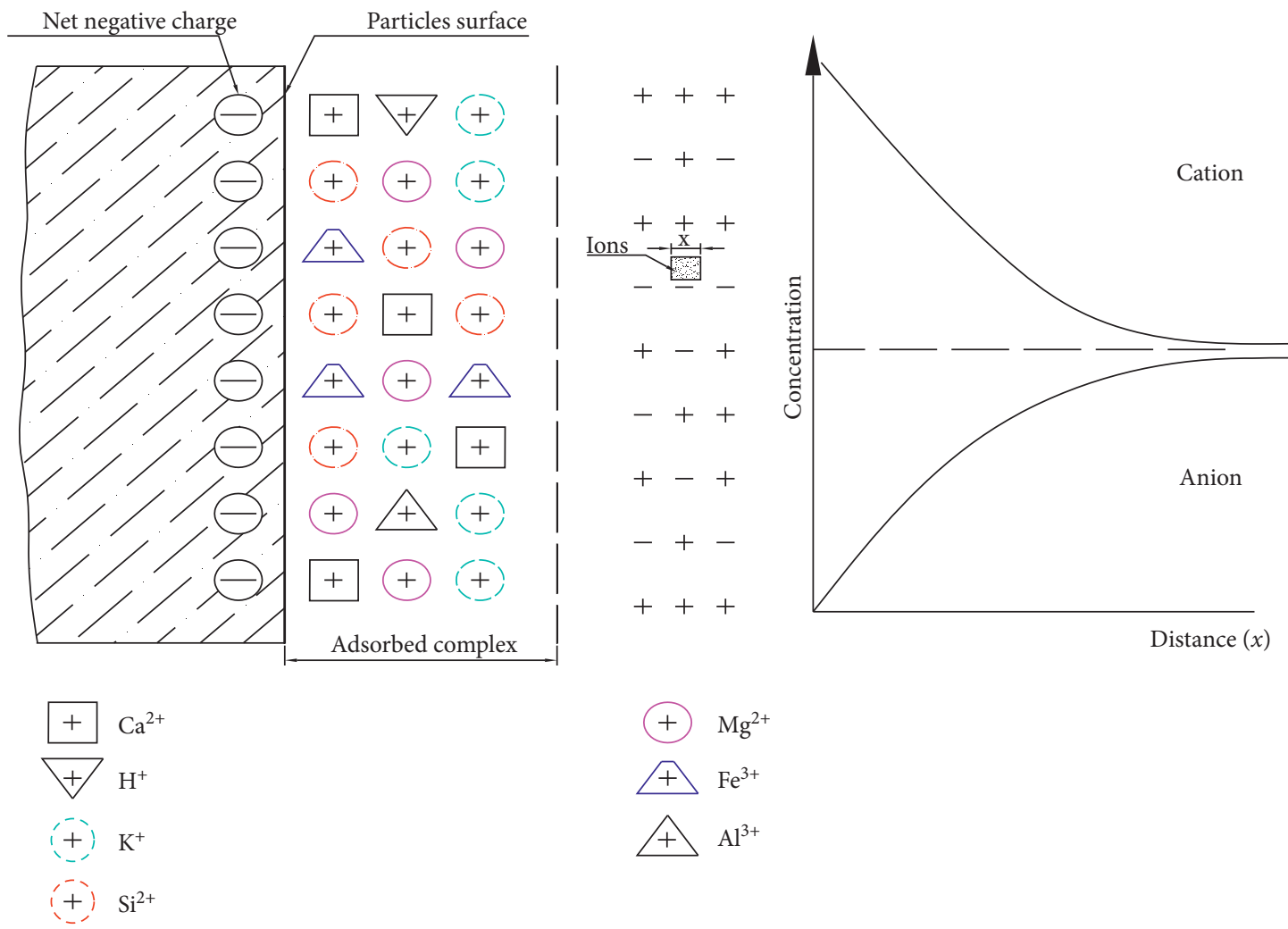

FIgURE 1: Release of ions and cation migration and exchange reaction in the adsorbed complex.

TABLE 1: Electrochemical series in order of ease of oxidation and displacement $[3,8]$.

\begin{tabular}{lclll}
\hline Metal & $\mathrm{Oxidation} \mathrm{reaction}$ & & \\
\hline Lithium & $\mathrm{Li}(s) \longrightarrow \mathrm{Li}^{+}(a q)$ & + & $e^{-}$ \\
Potassium & $\mathrm{K}(s) \longrightarrow \mathrm{K}^{+}(a q)$ & + & $e^{-}$ \\
Barium & $\mathrm{Ba}(s) \longrightarrow \mathrm{Ba}^{2+}(a q)$ & + & $2 e^{-}$ \\
Calcium & $\mathrm{Ca}(s) \longrightarrow \mathrm{Ca}^{2+}(a q)$ & + & $2 e^{-}$ \\
Sodium & $\mathrm{Na}(s) \longrightarrow \mathrm{Na}^{+}(a q)$ & + & $e^{-}$ \\
Magnesium & $\mathrm{Mg}(s) \longrightarrow \mathrm{Mg}^{2+}(a q)$ & + & $2 e^{-}$ \\
Aluminium & $\mathrm{Al}(s) \longrightarrow \mathrm{Al}^{3+}(a q)$ & + & $3 e^{-}$ \\
Manganese & $\mathrm{Mn}(s) \longrightarrow \mathrm{Mn}^{2+}(a q)$ & + & $2 e^{-}$ \\
Zinc & $\mathrm{Zn}(s) \longrightarrow \mathrm{Zn}^{2+}(a q)$ & + & $2 e^{-}$ \\
Chromium & $\mathrm{Cr}(s) \longrightarrow \mathrm{Cr}^{2+}(a q)$ & + & $3 e^{-}$ \\
Iron & $\mathrm{Fe}(s) \longrightarrow \mathrm{Fe}^{2+}(a q)$ & + & $2 e^{-}$ \\
Cobalt & $\mathrm{Co}(s) \longrightarrow \mathrm{Co}^{2+}(a q)$ & + & $2 e^{-}$ \\
Nickel & $\mathrm{Ni}(s) \longrightarrow \mathrm{Ni}^{2+}(a q)$ & + & $2 e^{-}$ \\
Tin & $\mathrm{Sn}(s) \longrightarrow \mathrm{Sn}^{2+}(a q)$ & + & $2 e^{-}$ \\
Lead & $\mathrm{Pb}(s) \longrightarrow \mathrm{Pb}^{2+}(a q)$ & + & $2 e^{-}$ \\
Hydrogen & $\mathrm{H}(g) \longrightarrow 2 \mathrm{H}^{+}(a q)$ & + & $2 e^{-}$ \\
Copper & $\mathrm{Cu}(s) \longrightarrow \mathrm{Cu}^{2+}(a q)$ & + & $2 e^{-}$ \\
Silver & $\mathrm{Ag}(s) \longrightarrow \mathrm{Ag}^{+}(a q)$ & + & $e^{-}$ \\
Mercury & $\mathrm{Hg}(l) \longrightarrow \mathrm{Hg}^{2+}(a q)$ & + & $2 e^{-}$ \\
Platinum & $\mathrm{Pt}(s) \longrightarrow \mathrm{Pt}^{2+}(a q)$ & + & $2 e^{-}$ \\
Gold & $\mathrm{Au}(s) \longrightarrow \mathrm{Au}^{3+}(a q)$ & + & $3 e^{-}$ \\
\hline
\end{tabular}

problem. Tables 3 and 4 represent the clayey soil classification related to plasticity according to Gopal and Rao [9], V. N. S. Murthy [10], and Das and Sobhan [8]. They in relation to the plasticity evaluation in percentage describe the plastic behavior of soils to enable designers to really understand the extent of plastic failure in clayey soils when exposed to loading. These range from nonplastic, low plastic, medium plastic, and to highly plastic according to Gopal and Roa [9] and V. N. S. Murthy [10] and from nonplastic, slightly plastic, low plastic, medium plastic, highly plastic, and to very highly plastic. These are the severity conditions in terms of the plasticity of the clayey soil. Table 5 shows clayey soils degree of expansion related to swelling potential $\left(w_{S}(\%)=0.00216 * I_{P}^{2.44}\right)$ according to Seed et al. [21]. The expression shows the direct relationship between swelling potential and plasticity of clayey soils. The swelling potential data further provide guiding standards or information on what to expect during chemical additive soil stabilization. The outcome of pozzolanic reactions, which are preceded by hydration, calcination, and carbonation, is the flocculation of dispersed clayey soil particles so as to form a dense and stabilized structure. This outcome is also monitored with the standard values contained in the tables as discussed above. 
TaвLe 2: Values of liquid limit, plastic limit, and activity of some clay minerals [8].

\begin{tabular}{lccc}
\hline Mineral & Liquid limit, $w_{L}(\%)$ & Plastic limit, $w_{P}(\%)$ & Activity, A \\
\hline Kaolinite & $35-100$ & $20-40$ & $0.3-0.5$ \\
Illite & $60-120$ & $35-60$ & $0.5-1.2$ \\
Montmorillonite & $100-900$ & $50-100$ & $1.5-7.0$ \\
Halloysite 1 & $50-70$ & $40-60$ & $0.1-0.2$ \\
Halloysite 2 & $40-55$ & $30-45$ & $0.4-0.6$ \\
Attapulgite & $150-250$ & $100-125$ & $0.4-1.3$ \\
Allophane & $200-250$ & $120-150$ & $0.4-1.3$ \\
\hline
\end{tabular}

TABle 3: Soil classification related to plasticity index $[9,10]$.

\begin{tabular}{lcccc}
\hline$I_{P}(\%)$ & 0 & $<7$ & $7-17$ & $>17$ \\
\hline Soil description & Nonplastic & Low plastic & Medium plastic & Highly plastic \\
\hline
\end{tabular}

TABLE 4: Soil classification related to plasticity index [8].

\begin{tabular}{lcccccc}
\hline$I_{P}(\%)$ & 0 & $1-5$ & $5-10$ & $10-20$ & $20-40$ & $>40$ \\
\hline Soil description & Nonplastic & Slightly plastic & Low plasticity & Medium plasticity & High plasticity & Very high plasticity \\
\hline
\end{tabular}

2.3. Inorganic Additive-Induced Pozzolanic Reaction. It has been of conventional interest to utilize cement, fly ash, metal slag, quicklime, hydrated lime, and calcite in the stabilization of clayey soils notwithstanding the hazards associated with their use and their greenhouse effect [22-24]. However, the primary focus is to review the benefits of these inorganic chemical compounds to trigger pozzolanic reaction in clayey soil stabilization $[3,4,7,8]$. Portland cement has been in use for quite some centuries now. The primary components in cement, metal slag, hydrated lime, quicklime, and calcite as presented in $\mathrm{Ta}$ ble 6 are the $\mathrm{CaO}$ as presented in Figure 2. This is the metallic compound responsible for the calcination reaction when mixed with hydrated clayey soil during a stabilization process. The utilization of these additives releases calcium ion which displaces hydrogen ions in the adsorbed complex as discussed above and reacts with the aluminosilica from soil and hydroxyl ion from the dipole adsorbed moisture to form calcium aluminosilicate hydrate (C-A-S-H) (see Figure 2) in the clayey soil particle double diffused layer forming flocculants. These flocculants settle and strengthening is achieved in the treated soil [9].

2.4. Organic Additive-Induced Pozzolanic Reaction. With the advent of the effort to achieve environmentally friendly earth work in geoenvironmental engineering, the application of materials with no carbon footprint, i.e., the utilization of environmentally friendly binding materials has been at the center of civil engineering activities [25-27]. Table 7 presents the chemical oxide composition of the amorphous materials derived from the direct combustion of biomass and some selected solid wastes. It can be observed that the primary oxide composition of these ash materials is alumina-silicaferrite as presented in Figure 3, which satisfies the basic requirement for pozzolanas according to design standards $[5,6]$. In addition, with a remarkable composition by weight is calcium oxide $(\mathrm{CaO})$. Therefore, during a soil stabilization procedure as discussed earlier, either of these ashes is mixed with hydrated clayey soil which has dipole hydrogen and hydroxyl ions in its adsorbed moisture [3, 4, 8, 9]. Aluminum, silicon, or iron ions from the ionized primary components of the ashes being higher in the electrochemical series have the tendency to displace hydrogen ions in the adsorbed moisture of the dispersed clayey soil to form denser clogs or flocs in a pozzolanic reaction. It is important to note that research results have shown that this pozzolanic process leads to improved clayey soil properties. In addition, contained in the lattice structure of the clayey soil is the sodium ion, which is responsible for the swelling behavior of clays. This element $(\mathrm{Na})$ is also displaced by calcium during the calcination reaction to reduce its volume change influence in clayey soils.

\section{Discussion of Results}

The entire effort of clayey soil treatment focusing on the improvement of the expansive and plastic properties and other engineering properties of the soil is to achieve the formation of C-A-S-H as presented in Figure 4. This is the component achieved through a pozzolanic reaction responsible for the alteration of the properties of clayey soils $[3,4]$. When clayey soils come in contact with moisture, which they do either during the soil stabilization procedures or during the service life of the foundation structures as they are exposed to moisture by runoff, migration through cracks, or pores or suction as the water table rises in a hydraulically bound condition, they experience volume changes. Very highly expansive soils with a swelling potential of $25 \%$ and above according to Seed et al. [21] and highly plastic soils 
TABLE 5: Clayey soils degree of expansion related to swelling potential $\left(w_{S}(\%)=0.00216 * I_{P}^{2.44}\right)[21]$.

\begin{tabular}{lcccc}
\hline Degree of expansion & Very high & High & Medium & Low \\
\hline Swelling potential, $w_{S}(\%)$ & $>25$ & $5-25$ & $1.5-5$ & $0-1.5$ \\
\hline
\end{tabular}

TABle 6: Chemical oxide composition of selected inorganic clayey soil binders [16, 18, 25-27].

\begin{tabular}{|c|c|c|c|c|c|c|}
\hline \multirow{2}{*}{ Oxides } & \multicolumn{6}{|c|}{ Chemical composition by weight (\%) } \\
\hline & Cement & Fly ash & Metal slag & Hydrated lime & Quicklime & Calcites \\
\hline $\mathrm{SiO}_{2}$ & 20.7 & 55.4 & 14.23 & 0.14 & 1.69 & - \\
\hline $\mathrm{Fe}_{2} \mathrm{O}_{3}$ & 4.41 & 7.84 & 35.65 & 0.17 & 0.384 & - \\
\hline $\mathrm{Al}_{2} \mathrm{O}_{3}$ & 11 & 28.4 & 5.23 & 0.11 & 0.325 & - \\
\hline $\mathrm{CaO}$ & 57.7 & 1.59 & 35.01 & 74.23 & 79.7 & 75 \\
\hline $\mathrm{MgO}$ & 1.24 & 2.86 & 2.95 & 0.74 & 2.40 & - \\
\hline $\mathrm{Na}_{2} \mathrm{O}$ & 0.23 & 0.59 & 0.31 & - & - & - \\
\hline $\mathrm{K}_{2} \mathrm{O}$ & 2.11 & 2.09 & 0.15 & - & 0.0504 & - \\
\hline $\mathrm{SO}_{3}$ & 1.96 & 0.09 & - & - & 0.104 & - \\
\hline $\mathrm{CO}_{2}$ & - & - & - & - & - & 25 \\
\hline $\mathrm{CaSO}_{4}$ & - & - & - & 0.12 & - & - \\
\hline $\mathrm{Cl}$ & - & - & - & - & 0.0267 & - \\
\hline $\mathrm{TiO}_{2}$ & - & - & 0.62 & - & - & - \\
\hline $\mathrm{MnO}$ & - & - & 3.60 & - & 1.12 & - \\
\hline $\mathrm{P}_{2} \mathrm{O}_{5}$ & - & - & 1.34 & 0.08 & 0.00788 & - \\
\hline LOI & 0.65 & 1.14 & 0.88 & 24.35 & - & - \\
\hline
\end{tabular}

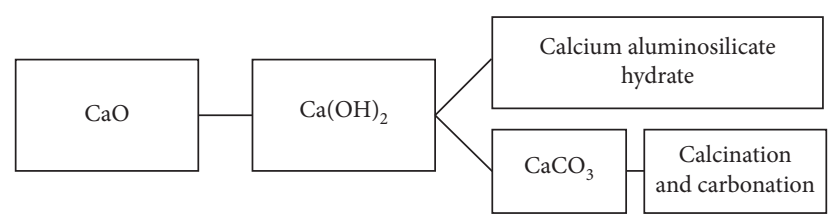

FIGURE 2: Inorganic reaction part of pozzolanic reaction.

TABLE 7: Chemical oxide composition of the additive materials [15, 17, 27-30].

\begin{tabular}{lcccccccccccccc}
\hline \multirow{2}{*}{ Materials } & \multicolumn{10}{c}{ Oxide composition (content by weight, \%) } \\
& $\mathrm{SiO}_{2}$ & $\mathrm{Al}_{2} \mathrm{O}_{3}$ & $\mathrm{CaO}$ & $\mathrm{Fe}_{2} \mathrm{O}_{3}$ & $\mathrm{MgO}$ & $\mathrm{K}_{2} \mathrm{O}$ & $\mathrm{Na}_{2} \mathrm{O}$ & $\mathrm{TiO}_{2}$ & $\mathrm{LOI}$ & $\mathrm{P}_{2} \mathrm{O}_{5}$ & $\mathrm{SO}_{3}$ & $\mathrm{ZnO}^{2}$ & $\mathrm{Free} \mathrm{CaO}$ \\
\hline PBA & 60.96 & 15.49 & 14.59 & 0.45 & 0.89 & - & 0.81 & - & 5.8 & - & - & - & - \\
RHA & 56.48 & 22.72 & 5.56 & 3.77 & 4.65 & 2.76 & 0.01 & 3.17 & 0.88 & - & - & - & - \\
WTA & 14.1 & 2.7 & 47.0 & 1.1 & 0.7 & 0.01 & 0.01 & 0.01 & - & 0.01 & 1.2 & 33.1 & - \\
WPA & 28.15 & 15.77 & 30.52 & 1.05 & 1.94 & 0.45 & 0.67 & - & 17.23 & - & 0.57 & - & - \\
SBA & 57.95 & 8.23 & 4.52 & 3.96 & 4.47 & 2.41 & - & - & 5.0 & - & - & - \\
\hline
\end{tabular}

PBA: palm bunch ash; RHA: rice husk ash; WTA: waste tire ash; WPA: waste paper ash; SBA: sugarcane bagasse ash; LOI: loss on ignition.

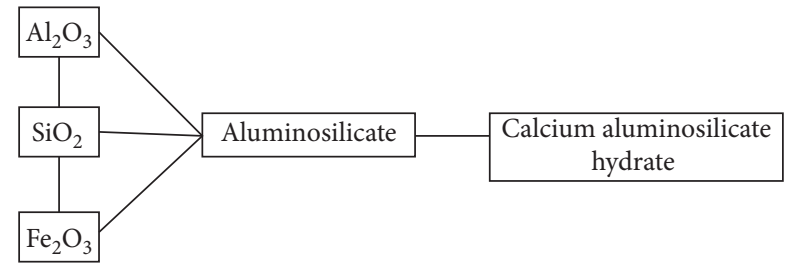

FIGURE 3: Organic reaction part of pozzolanic reaction. with a consistency index of $17 \%$ and above according to Gopal and Rao [9] and V. N. S. Murthy [10] or 20\% and above according to Das and Sobhan [8] belong to this group. It can be observed in Figure 4 that $\mathrm{CaO}$, which is a major component of both the organic and inorganic chemical additives, goes through a hydration process as soon as it comes in contact with the adsorbed moisture in a soil stabilization procedure. This results in hydrated calcium oxide 


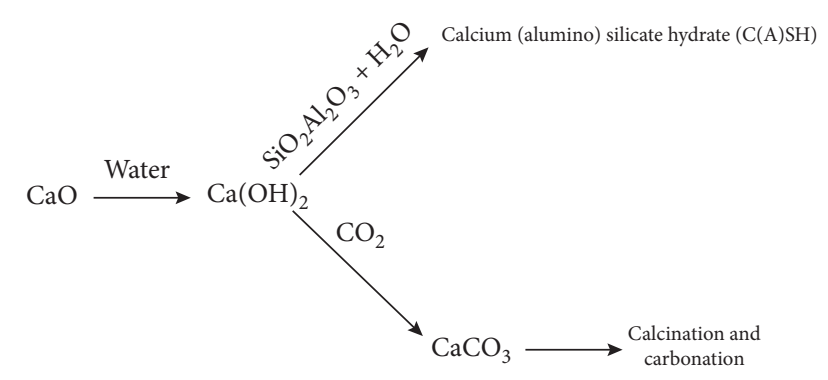

FIGURE 4: Specific reaction paths for hydration, calcination, carbonation, and pozzolanic reactions of soil treatment.

$\left(\mathrm{Ca}(\mathrm{OH})_{2}\right)$. This compound undergoes either carbonation to give calcite or pozzolanic reaction in the presence of alumina and silica and further hydration of $\mathrm{CaO}$ leading to the formation of the compounds responsible for flocculant formation in clayey soils (C-A-S-H or C-A-H and C-S-H).

\section{Conclusions}

The improvement of the engineering properties of highly expansive clayey soils through hydration, calcination, and carbonation reactions leading through the pozzolanic reaction which forms flocculants and densified mass of soil has been reviewed. It can be concluded that calcium oxide, alumina, silica, and ferrite are the compounds and elements in aqueous medium (hydrated medium) that trigger a pozzolanic reaction that binds the dispersed particles of clayey soil together by increasing or improving the van der Waal's interparticle forces to form a bonded mass of soil. The release of these pozzolanic components is achieved with either organic or inorganic admixtures. However, to achieve earth work in this era of global warming without any carbon footprint, this review proposes the application of organic additives to achieve pozzolanic reaction and consequently clayey soil stabilization.

\section{Data Availability}

The data used to support the findings of this study are presented within this article.

\section{Conflicts of Interest}

The authors declare that they have no known competing financial interest or personal relationships that could have appeared to influence the work reported in this study.

\section{References}

[1] S. Baram, Z. Ronen, D. Kurtzman, C. Külls, and O. Dahan, "Desiccation-crack-induced salinization in deep clay sediment," Hydrology and Earth System Sciences, vol. 17, no. 4, pp. 1533-1545, 2013.

[2] K. C. Onyelowe, F. D. A. Onyelowe, D. Bui Van et al., "Valorization and sequestration of hydrogen gas from biomass combustion in solid waste incineration $\mathrm{NaOH}$ oxides of carbon entrapment model (SWI-NaOH-OCE Model),"
Materials Science for Energy Technologies, vol. 3, pp. 250-254, 2020.

[3] D. Bui Van and K. C. Onyelowe, "Adsorbed complex and laboratory geotechnics of Quarry Dust (QD) stabilized lateritic soils," Environmental Technology and Innovation, vol. 10, pp. 355-368, 2018.

[4] R. E. Grim, Clay Mineralogy, McGraw-Hill Book Company, Inc., London, UK, 1953.

[5] BS 8615-1, Specification for Pozzolanic Materials for Use with Portland Cement. Natural Pozzolana and Natural Calcined Pozzolana, British Standard International, London, UK, 2019.

[6] American Standard for Testing and Materials (ASTM) C618, Specification for Pozzolanas, ASTM International, Philadelphia, PA, USA, 1978.

[7] I. Shigeki and S. Toshio, Chemical Reactions Among Clay Minerals' Calcium Carbonate, And Ammonium Chloride, The American Mineralogist, New York, NY, USA, 1965.

[8] B. M. Das and K. Sobhan, Principles of Geotechnical Engineering, Cengage Learning, Stamford, CT, USA, 8th edition, 2012.

[9] R. Gopal and A. S. R. Rao, Basic and Applied Soil Mechanics, New Age International Publishers, New Delhi, India, 2011.

[10] V. N. S. Murthy, Advanced Geotechnical Engineering; Geotechnical Engineering Series, CBS Publishers and Distributors, New Delhi, India, 2007.

[11] AASHTO, Guide for Design of Pavement Structures, American Association of State Highway and Transportation Officials (AASHTO), Washington DC, USA, 1993.

[12] S. Haas and H.-J. Ritter, "Soil improvement with quicklime long-time behaviour and carbonation," Road Materials and Pavement Design, vol. 20, no. 8, pp. 1941-1951, 2019.

[13] J. F. Rivera, A. Orobio, R. Mejia de Gutierrez et al., "Clayey soil stabilization using alkali-activated cementitious materials," Materiales de Construccion, vol. 70, no. 337, pp. 1-12, 2020.

[14] K. C. Onyelowe, J. C. Aririguzo, and C. N. Ezugwu, Sustainable Soils Re-Engineering, Partridge Publishing, Singapore, 2019.

[15] K. C. Onyelowe, D. Bui Van, O. Ubachukwu et al., "Recycling and reuse of solid wastes; a hub for ecofriendly, ecoefficient and sustainable soil, concrete, wastewater and pavement reengineering," International Journal of Low-Carbon Technologies, vol. 14, no. 3, pp. 440-451, 2019.

[16] K. C. Onyelowe, A. B. Salahudeen, A. O. Eberemu et al., "Oxides of carbon entrapment for environmentally friendly geomaterials ash derivation," in Recent Thoughts in Geoenvironmental EngineeringSSIGE), Cairo, Egypt, 2020.

[17] K. C. Onyelowe, A. B. Salahudeen, A. O. Eberemu et al., "Utilization of solid waste derivative materials in soft soils Reengineering," in Recent Thoughts in Geoenvironmental EngineeringSSIGE), Cairo, Egypt, 2020.

[18] D. L. Rimmer and D. J. Greenland, "Effects of calcium carbonate on the swelling behaviour of a soil clay," Journal of Soil Science, vol. 27, no. 2, pp. 129-139, 1976.

[19] A. Lasledj and M. Al-Mukhtar, "Effect of hydrated lime on the engineering behaviour and the microstructure of highly expansive clay," in Proceedings of the 12th International Conference of International Association for Computer Methods and Advances in Geomechanics (IACMAG), pp. 1-6, Goa, India, October 2008.

[20] N. W. Soon, L. M. Lee, T. C. Khun, and H. S. Ling, "Improvements in engineering properties of soils through microbial-induced calcite precipitation," KSCE Journal of Civil Engineering, vol. 17, no. 4, pp. 718-728, 2013. 
[21] H. B. Seed, R. J. Woodward, and R. Lundgren, "Prediction of swelling potential for compacted clays," Journal of the Soil Mechanics and Foundations Division, vol. 88, no. 3, pp. 53-87, 1962.

[22] N. A. Hafshejani and S. Jafari, "The study of particle size distribution of calcium carbonate and its effects on some soil properties in khuzestan province," Iran Agricultural Research, vol. 36, no. 2, pp. 71-80, 2017.

[23] R. Yazarloo, M. Golestani, M. Asadi, and S. Ebrahimi, "Adding calcite and nanocalcite to improving the plastic properties of the lean clay," in Proceedings of the 3rd World Congress on New Technologies (NewTech'17), Rome, Italy, June 2017.

[24] A. A. Amadi and A. Okeiyi, "Use of quick and hydrated lime in stabilization of lateritic soil: comparative analysis of laboratory data," International Journal of Geo-Engineering, vol. 8, no. 1, 2017.

[25] H. Peron, L. Laloui, T. Hueckel, and B. Liang, "Desiccation cracking of soils," European Journal of Environmental and Civil Engineering, vol. 13, no. 7-8, pp. 869-888, 2009.

[26] B. Liu, C. Zhu, C.-S. Tang et al., "Bio-remediation of desiccation cracking in clayey soils through microbially induced calcite precipitation (MICP)," Engineering Geology, vol. 264, 2020.

[27] K. C. Onyelowe, D. Bui Van, L. Dao-Phuc et al., "Evaluation of index and compaction properties of lateritic soils treated with quarry dust based geopolymer cement for subgrade purpose," Epitoanyag - Journal of Silicate Based and Composite Materials, vol. 72, no. 1, pp. 12-15, 2020.

[28] R. S. Almenares, L. M. Vizcaíno, S. Damas, A. Mathieu, A. Alujas, and F. Martirena, "Industrial calcination of kaolinitic clays to make reactive pozzolans," Case Studies in Construction Materials, vol. 6, pp. 225-232, 2017.

[29] J. A. Baldovino, E. B. Moreira, W. Teixeira, R. L. S. Izzo, and J. L. Rose, "Effects of lime addition on geotechnical properties of sedimentary soil in Curitiba, Brazil," Journal of Rock Mechanics and Geotechnical Engineering, vol. 10, no. 1, pp. 188-194, 2018.

[30] J. Pastor, R. Tomás, M. Cano, A. Riquelme, and E. Gutiérrez, "Evaluation of the improvement effect of limestone powder waste in the stabilization of swelling clayey soil," Sustainability, vol. 11, no. 3, p. 679, 2019. 